\title{
The Outcomes of Endotracheal Intubation Versus Non-Endotracheal Intubation During Cardiopulmonary Arrest in the Emergency Department
}

\author{
Abdullah A. Bakhsh', ${ }^{1}$ MBBS, FAAEM, Daniah S. Allali' ${ }^{2}$, MBBS \\ Ahmad H. Bakhribah', MBBS, and Ali A. Faydhi ${ }^{3}$, MRCP,EDIC \\ ${ }^{1}$ Department of Emergency Medicine and ${ }^{3}$ Department of Intensive Care Unit \\ Faculty of Medicine, King Abdulaziz University, Jeddah, Saudi Arabia \\ ${ }^{2}$ Department of Emergency Medicine, King Abdulaziz Medical City, Riyadh, Saudi Arabia
}

\section{Correspondence}

Dr. Abdullah A. Bakhsh

Department of Emergency Medicine

King Abdulaziz University

P.O. Box 80215

Jeddah 21589, Saudi Arabia

e.M: aarbakhsh@kau.edu.sa

\section{Submission: 21 Nov. 2018 \\ Accepted: 06 Jan. 2019}

\section{Citation}

Bakhsh AA, Allali DS, Bakhribah AH, Faydhi AA. The outcomes of endotracheal intubation versus non-endotracheal intubation during cardiopulmonary arrest in the emergency department. JKAU Med Sci 2019; 26 (1): 3-10. DOI: 10.4197/Med. 26-1.2

Copyright: (OThe Author(s), YEAR. Publisher. The Journal of King Abdualziz University - Medical Sciences is an Official Publication of "King Abdulaziz University". It is an open-access article distributed under the terms of the Creative Commons Attribution Non-Commercial License, which permit unrestricted non-commercial use, distribution, and reproduction in any medium, provided the original work is properly cited.

\begin{abstract}
Airway management techniques during cardiopulmonary arrest in the emergency department may impact short and long-term outcomes of these patients. Prior studies addressing airway management of patients in cardiopulmonary arrest in the emergency department are limited. We aimed to evaluate the one-month neurological outcomes post cardiac arrest as a primary endpoint. Our secondary endpoint was to look at return of spontaneous circulation rates and survival to discharge. We retrospectively reviewed cardiac arrest flow sheets of patients sustaining in-emergency department cardiopulmonary arrest between January 2017 and September 2017. We looked at the different types of airway management techniques and their effect on patient outcomes. Patients who received non-endotracheal intubation during cardiopulmonary arrest had higher rates of good neurological outcome (GCS > 9) at one month when compared with patients who received endotracheal intubation: $8(32 \%)$ vs. $2(5.3 \%)$, respectively. Our results revealed a significant association of non-endotracheal intubation (bag-valve mask or laryngeal mask airway) with return of spontaneous circulation rates ( $p$ 0.044), survival to discharge $(p<$ $0.001)$, and good neurological outcome (GCS > 9) ( $p$ 0.008). Although non-endotracheal intubation during cardiopulmonary arrest is not common, we encourage the increased use of bag-valve mask and laryngeal mask airways during cardiopulmonary arrest as they are associated with better outcomes..
\end{abstract}

\section{Keywords}

Cardiopulmonary arrest; Airway management in cardiac arrest 


\section{Introduction}

$R$ ecent science in cardiac arrest focuses more on chest compression quality than on definitive airway placement during cardiopulmonary resuscitation $(\mathrm{CPR})^{[1,2]}$. Nonetheless, tracheal intubation remains ubiquitous during in-hospital cardiac arrest ${ }^{[3,4]}$. Prioritizing airway and breathing has led to increased hands-off time during tracheal intubation attempts ${ }^{[5]}$. This results in a reduction of forward flow to major organs ${ }^{[6]}$. The compromise in cerebral and coronary perfusion pressures leads to poor neurological outcomes and lower rates of return of spontaneous circulation (ROSC) ${ }^{[6]}$. Cardiopulmonary resuscitation is a complex procedure with opportunities for distraction from the main purpose: to restore partial flow of oxygenated blood to the brain and heart. Endotracheal intubation commonly results in interruption of quality chest compressions ${ }^{[7,8]}$. Airway management via endotracheal intubation has been the standard for many years, until 2010 when the American Heart Association deemphasized airway prioritization during cardiac arrest ${ }^{[1]}$. Nonetheless, endotracheal intubation remains to be prioritized during in-hospital cardiac arrest ${ }^{[3,4]}$. This is mainly due to inadequate in-hospital evidence and unclear direction in airway management during cardiac arrest $t^{[2,9]}$. Additionally, unlearning a procedure that has been performed for many years presents a major challenge in the healthcare setting ${ }^{[10]}$. There have been multiple studies questioning the survival benefit of endotracheal intubation compared with non-endotracheal intubation in the pre-hospital setting ${ }^{[11-17]}$. A meta-analysis concluded that out-ofhospital cardiac arrest victims who receive endotracheal intubation by emergency medicine services are more likely to obtain ROSC ${ }^{[18]}$. Recently, Andersen et al., ${ }^{[3]}$ demonstrated that early endotracheal intubation during cardiac arrest is not associated with increased survival benefit in-hospital. We could not find studies addressing airway intervention techniques on cardiac arrest outcomes in the emergency department (ED) setting ${ }^{[19,20]}$. The aim of this study was to evaluate the association between different airway management techniques (endotracheal intubation vs. nonendotracheal intubation) and outcome variables (good neurological outcome at one-month, ROSC, survival to discharge) for cardiopulmonary arrest patients in a single ED.

Endotracheal intubation is the most commonly performed airway procedure during a cardiopulmonary arrest in the in-hospital setting ${ }^{[3,4]}$. Laryngeal mask airways and bag-valve mask are used less frequently perhaps due to lack of training or the conception that they are inferior to endotracheal intubation. Additionally, the American Heart Association and European Resuscitation Council Guidelines do not provide clear direction on which airway device to use during cardiopulmonary arrest ${ }^{[2,9]}$. However, the emphasis remains on high quality chest compressions and minimizing interruptions. Therefore, it is prudent to use an airway device that causes less interruption in chest compressions.

\section{Material and Methods}

\section{Study Design and Population}

After obtaining institutional review board approval at King Abdulaziz University (reference number 59217) we conducted a retrospective chart review of cardiopulmonary arrests occurring in the ED at King Abdulaziz University Hospital from January 2017 to September 2017. King Abdulaziz University Hospital is a university hospital with an approximate ED visit rate of 66,000 per year. A total of 130 cardiopulmonary arrests occurred in the ED during the study period. We included all patients during the study period who met the following criteria: age $\geq 18$ years old, in-ED cardiopulmonary arrests (occurring within 24 hours of triage time), and patients without advanced airway in place. We excluded patients less than 18 years old, Do-Not-Resuscitate order in place, pre-hospital cardiopulmonary arrest, boarding in the ED $\geq 24$ hours, prior invasive airway device in place, pregnancy, and traumatic arrests.

\section{Endpoints}

Our primary endpoint was good neurological outcome (defined as Glasgow Coma Scale (GCS > 9) at onemonth post-cardiac arrest. Our secondary endpoints were ROSC and survival to discharge.

\section{Setting}

Upon recognition of a cardiopulmonary arrest (absent palpable pulse and respirations) in the ED, chest compressions are started immediately, while another healthcare provider is prompted to make an overhead announcement in the department. The resuscitation team is composed of emergency physicians and nurses certified in advanced cardiac life support (ACLS). A cardiac arrest flow sheet is completed in real-time 
by a designated nurse trained in documentation. The flow sheet contains date/time of arrest, patient information, type of airway device, time of airway device placement, name/level of airway operator, initial and subsequent rhythms, medications administered, admitting diagnosis, ROSC, names/position of all team members, and additional nurse/physician notes. The standard airway intervention is endotracheal intubation during the arrest. This is performed by a resident or specialist physician with prior experience in endotracheal intubation and laryngeal mask airway placement. Occasionally, endotracheal intubation is deferred, and bag-valve mask or laryngeal mask airways (LMA ${ }^{\oplus}$ Classic $^{\mathrm{TM}}$ Airway (Teleflex Headquarters International, Westmeath, Ireland)) are placed, at the leader's discretion. Capnography is used to confirm endotracheal tube placement after placement. Epinephrine is given at time intervals according to the ACLS protocol. Sodium bicarbonate, however, is given at the discretion of the treating physician. None of the patients were placed on targeted temperature management protocol post-cardiac arrest in the emergency department.

\section{Return of Spontaneous Circulation}

Restoration of palpable carotid pulse for at least 20 minutes $^{[21]}$.

\section{Data Collection}

Study investigators collected data directly from code blue forms. All collected data was then reviewed by principal investigator for confirmation in an attempt to reduce inter-rate reliability. Data was obtained from all cardiac arrest flow sheets based on the Utsteinstyle template. For patients with multiple cardiac arrests, only the first episode was included. This flow sheet is standard for all cardiac arrest patients occurring in-hospital who require chest compressions. It is completed in real-time by a nurse trained in ACLS documentation. Survival to discharge and neurological outcome at one-month was obtained from patient electronic medical records (Phoenix Health Systems (Medsphere, Carlsbad, CA)). This was collected by the study investigators and reviewed again by the principal investigator for confirmation. At this institution, neurologic outcomes are monitored using the GCS instead of cerebral performance category. Prior studies have demonstrated that GCS is a simple and reliable method for clinical outcome assessment post-cardiac $\operatorname{arres}^{[22,23]}$.

\section{Statistical Analysis}

Descriptive statistics were used to present initial rhythm, ROSC, survival to discharge and neurological outcomes for all patients. Chi-squared test was used to analyze the association of type of airway (endotracheal intubation vs. non-endotracheal intubation) with gender, initial rhythm, ROSC, survival to discharge, and neurological outcome.

The analysis was performed in $95 \%$ confidence interval using IBM SPSS Statistics for Windows, Version 20 (IBM Corp., Armonk, NY USA).

\section{Results}

Our study included all 63 patients in the emergency department from a single center during the study period. Thirty-five $(55.56 \%)$ were male and the study population had a mean age of $63.02 \pm 16.75$. The mean duration of CPR was $14.37 \pm 16.47$ minutes, whereas, the mean time to endotracheal tube placement in the endotracheal intubation (ETI) group was $6.59 \pm$ 5.43 minutes. Sodium bicarbonate is administered in $28(44.44 \%)$ patients. The most commonly seen initial rhythm was pulseless electrical activity (54.97\%), followed by asystole (38.10\%), and ventricular fibrillation (7.94\%). Endotracheal intubation occurred in $38(60.35 \%)$ patients, followed by bag-valve mask in 21 (33.33\%) patients, and laryngeal mask airway in only 4 (6.35\%) patients. Return of spontaneous circulation rate was observed in $50(79.37 \%)$ patients, survival to hospital discharge in $11(17.46 \%)$ patients and good neurological outcome (GCS > 9) in $10(15.87 \%)$ patients. (Table 1)

Baseline characteristics of age, gender, initial rhythms, duration of CPR, and bicarbonate administration among patients receiving endotracheal intubation and non-endotracheal intubation were not statistically different. (Table 2 )

\section{Association of Type of Airway Device with Out- come Variables}

A total of $38(60.3 \%)$ received endotracheal intubation during cardiac arrest. Patients intubated during cardiopulmonary arrest had lower ROSC rates, lower survival to discharge, and bad neurological outcome $(\mathrm{GCS} \leq 9)$ when compared with patients who did not receive endotracheal intubation during cardiac arrest (Table 3). Our results revealed a significant association 
The Outcomes of Endotracheal Intubation Versus Non-Endotracheal Intubation During Cardiopulmonary Arrest in the ER Dept. A.A. Bakhsh et al.

Table 1. Overall prevalence of initial rhythm return of spontaneous circulation, survival to discharge, good neurological outcome $(n=63)$.

\begin{tabular}{|l|c|}
\hline \multicolumn{1}{|c|}{ Variables } & N (\%) \\
\hline Age (mean \pm SD) & $63.02 \pm 16.75$ \\
\hline Gender: Male & $35(55.56 \%)$ \\
\hline CPR Duration (mean \pm SD) & $14.37 \pm 16.47$ \\
\hline Bicarbonate Administration & $28(44.44 \%)$ \\
\hline Mean Time to ETI (mins) (mean \pm SD) $(\mathrm{n}=37)$ & $6.59 \pm 5.43$ \\
\hline Type of Airway & \\
\hline Endotracheal Intubation & $38(60.35 \%)$ \\
\hline Bag-Valve Mask & $21(33.33 \%)$ \\
\hline Laryngeal Mask Airway & $4(6.35 \%)$ \\
\hline Initial Rhythm & \\
\hline Pulseless Electrical Activity & $34(54.97 \%)$ \\
\hline Asystole & $24(38.10 \%)$ \\
\hline Ventricular Fibrillation & $5(7.94 \%)$ \\
\hline Return of Spontaneous Circulation & \\
\hline Yes & $50(79.37 \%)$ \\
\hline No & $13(20.63 \%)$ \\
\hline Survival to Discharge & $11(17.46 \%)$ \\
\hline Yes & $52(82.54 \%)$ \\
\hline No & \\
\hline Neurological Outcome & $10(15.87 \%)$ \\
\hline Good (GCS >9) & $50(79.37 \%)$ \\
\hline Bad & $3(4.76 \%)$ \\
\hline Not Documented & \\
\hline CPR: Cardiopulmonary resuscitation; ETI: Endotracheal intubation; G(S: Glasgow Coma Scale \\
\hline
\end{tabular}

Table 2. Association between baseline characteristics (age, gender, initial rhythm, duration of cardiopulmonary resuscitation, bicarbonate administration) with type of airway (endotracheal intubation vs. non-endotracheal intubation). ( $n=63)$.

\begin{tabular}{|l|c|c|c|}
\hline & ETI $(\mathbf{n}=\mathbf{3 8})$ & Non-ETI $(\mathbf{n}=\mathbf{2 5})$ & $\mathbf{p}$-value \\
\hline Age (years) & $66.76 \pm 17.92$ & $57.32 \pm 14.79$ & 0.275 \\
\hline Gender & & & 0.645 \\
\hline Male & $22(57.91 \%)$ & $13(52.02 \%)$ & \\
\hline Female & $16(42.18 \%)$ & $12(48.04 \%)$ & \\
\hline Initial Rhythm & & & 0.561 \\
\hline Asystole & $14(36.81 \%)$ & $10(40.01 \%)$ & \\
\hline Pulseless electrical activity & $22(57.93 \%)$ & $12(48.04 \%)$ & \\
\hline Ventricular fibrillation & $2(5.37 \%)$ & $3(12.01 \%)$ & \\
\hline Duration of CPR (min) & $18.21 \pm 17.89$ & $8.52 \pm 8.10$ & 0.099 \\
\hline Bicarbonate administration & $18(28.63 \%)$ & $10(15.97 \%)$ & 0.565 \\
\hline
\end{tabular}

ETI: Endotracheal intubation; (PR: Cardiopulmonary resuscitation

Table 3. Association of type of airway (endotracheal intubation vs. non-endotracheal intubation) with return of spontaneous circulation, survival to discharge, and good neurological outcome.

\begin{tabular}{|c|c|c|c|}
\hline & ETI $(\mathbf{n}=\mathbf{3 8})$ & Non-ETI $(\mathbf{n}=\mathbf{2 5})$ & p-value \\
\hline Return of Spontaneous Circulation & & & .044 \\
\hline Yes & $27(71.15 \%)$ & $23(92.01 \%)$ & \\
\hline No & $11(28.98 \%)$ & $2(8.09 \%)$ & $<.001$ \\
\hline Survival to Discharge & & & \\
\hline Yes & $1(2.61 \%)$ & $10(40.06 \%)$ & .008 \\
\hline No & $37(97.41 \%)$ & $15(60.08 \%)$ & \\
\hline Good neurological outcome (GCS $>9)$ & & & \\
\hline Yes & $2(5.31 \%)$ & $8(32.04 \%)$ & \\
\hline No & $35(92.13 \%)$ & $15(60.07 \%)$ & \\
\hline Not Documented & $1(2.61 \%)$ & $2(8.09 \%)$ & \\
\hline
\end{tabular}

GCS: Glasgow Coma Scale 
of non-endotracheal intubation (bag-valve mask or laryngeal mask airway) with ROSC rates ( $p$ 0.044), survival to discharge $(p<0.001)$, and good neurological outcome (GCS > 9) (p 0.008) (Table 3).

\section{Discussion}

In this retrospective review, we found that patients who underwent non-ETI airway (bag-valve mask or laryngeal mask airway) were associated with higher rates of ROSC, survival to discharge, and good neurological outcome when compared with patients who underwent ETI during ED cardiopulmonary arrest. It is important to note that additional variables of age, gender, initial rhythm, duration of CPR, and bicarbonate administration among the two groups (endotracheal intubation vs. non-endotracheal intubation) were not statistically significant (Table 2). This reduces confounding factors affecting resuscitation outcomes.

Multiple studies addressing airway techniques in cardiopulmonary arrests have been done in the out-of-hospital setting. A large observational study $(n=649,359)$ from Japan found that tracheal intubation during out-of-hospital cardiac arrest was associated with decreased odds of neurologically favorable survival ${ }^{[18]}$. Benoit et al. showed in a meta-analysis that patients receiving out-of-hospital endotracheal intubation by emergency medical services are more likely to obtain $\mathrm{ROSC}^{[24]}$. The out-of-hospital setting introduces an entirely different setting, environment, patient physiology, initial rhythms, etc. Additionally, all studies included in the meta-analysis had very low to low quality of evidence.

Studies addressing the same question in the in-hospital setting are scant. Tortolani et al., ${ }^{[25]}$ demonstrated that patients who were intubated during in-hospital cardiac arrest were associated with increased mortality. Andersen et al., ${ }^{[3]}$ demonstrated that initiation of tracheal intubation within the first 15 minutes of in-hospital cardiac arrest, is associated with decreased survival to hospital discharge. Our study demonstrates findings consistent with Andersen et $a l .{ }_{.}{ }^{[3]}$; patients receiving endotracheal intubation during cardiopulmonary arrest had a mean time to endotracheal intubation of $6.59 \pm 5.43$ minutes.

This could be explained by many physiologic factors including less interruption in chest compressions, less hyperventilation, less delay in other interventions such as defibrillation, and less events of unrecognized esophageal intubation or tube dislodgment. All of which may lead to poorer outcomes. Endotracheal intubation during CPR is a complex procedure and may deviate the team's attention away from the primary objective; to maintain forward flow to critical organs. Additionally, the varying level of experience of the airway operator may result in multiple attempts at ETI, which is associated with poorer outcomes.

Even though duration of CPR between patients receiving ETI and non-ETI were not significant, the mean duration of CPR in the ETI group was longer (18.21 \pm 17.89$)$ compared with non-ETI group (8.52 \pm 8.10). It is unclear whether patients who had longer CPR were sicker or not, however, all these patients were admitted to the intensive care unit eventually. Hajbaghery et al., ${ }^{[26]}$ found that the mean duration of CPR for patients who survived to hospital discharge was $15.9 \pm 8.2$. Another study by Shih et al., ${ }^{\left[{ }^{[2]}\right.}$ showed a $90 \%$ cumulative discharge survival rate was recorded in patients receiving resuscitation duration of less than 30 minutes. It is important to note that only 4 out of 38 patients had CPR duration longer than 30 minutes in the ETI group. However, only 1 out of 25 had CPR duration longer than 30 minutes in the non-ETI group.

\section{Limitations}

The retrospective nature of the study brings up the question of data integrity and accuracy. Additionally, the small sample size and the descriptive analyses lower the likelihood of generating solid conclusions. Neurological outcome assessment using the GCS is not the standard measurement scale worldwide. This will yield results that are not generalizable and noncomparable with other studies. Cardiopulmonary arrest quality has a major impact on outcomes, however this data is not measured. The number of attempts to place an airway device is unknown. This is another factor that may play a role in the outcome. The duration of cardiopulmonary arrest is shorter in patients receiving non-endotracheal intubation. Therefore, the better outcomes in the non-endotracheal intubation group may be due to the shorter duration of CPR.

\section{Conclusions}

In our small and descriptive study we have found that non-endotracheal intubation (bag-valve mask or laryngeal mask airways) during adult cardiopulmonary arrest in the emergency department is associated with high rates of ROSC, survival to discharge, and good 
neurological outcomes. Although, we are unable to generate a solid generalizable conclusion to support non-endotracheal intubation over endotracheal intubation during cardiopulmonary arrest, the use of bag-valve mask and/or laryngeal mask airway is overall low at our institution. This is likely, due to the conception that these techniques are inferior to endotracheal intubation. Given we have found better outcomes with non-endotracheal intubation, we encourage the use of bag-valve mask and/or laryngeal mask airways more frequently. Future similar studies with larger sample size are needed to determine more robust analyses.

\section{Declarations}

Ethics approval and consent to participate: ethical approval was obtained via the unit of biomedical ethics and research committee at our institution (Reference number: 592-17).

\section{Conflict of Interest}

The authors have no conflict of interest.

\section{Disclosure}

The authors did not receive any type of commercial support either in forms of compensation or financial for this study. The authors have no financial interest in any of the products or devices, or drugs mentioned in this article.

\section{Ethical Approval}

The study design was reviewed and approved by the Unit of Biomedical Ethics Research Committee at King Abdulaziz University.

\section{Availability of Data and Material}

Available under results.

\section{Authors' Contribution}

Each author contributed in the collection of data, manuscript preparation, review of content and data.

\section{Acknowledgments}

Dr. Jameel Abualenein and Dr. Abdulrahman Bakhsh for general support and guidance. Ms. Amal Bakhsh for manuscript formatting and reference organization. Ms. Lauren Salisbury for reviewing overall spelling, grammar and sentence structure. Dr. Sara Alqarni for assisting with Arabic translation.

\section{References}

[1] Neumar R, Otto C, Link M, Kronick S, Shuster M, Callaway C, Kudenchuk P, Ornato J, Mcnally B, Silvers S, Passman R, White R, Hess E, Tang W, Davis D, Sinz E, Morrison L. Part 8: adult advanced cardiovascular life support: 2010 American Heart Association Guidelines for Cardiopulmonary Resuscitation and Emergency Cardiovascular Care. Circulation 2010; 122S(18 Suppl 3): S729-767.

[2] Link M, Berkow L, Kudenchuk P, Halperin H, Hess E, Moitra V, Neumar R, O'Neil B, Paxton J, Silvers S, White R, Yannopoulos D, Donnino M. Part 7: Adult Advanced Cardiovascular Life Support: 2015 American Heart Association Guidelines Update for Cardiopulmonary Resuscitation and Emergency Cardiovascular Care. Circulation 2015; 132(18 Suppl 2): S444-464.

[3] Andersen L, Granfeldt A, Callaway C, Bradley S, Soar J, Nolan J, Kurth T, Donnino M, American Heart Association's Get with the Guidelines-Resuscitation Investigators. Association between tracheal intubation during adult inhospital cardiac arrest and survival. JAMA. 2017; 317(5): 494-506.

[4] Kaki AM, Alghalayini KW, Alama MN, Almazroaa AA, Khathlan NAA, Sembawa H, Ouseph BM. An audit of inhospital cardiopulmonary resuscitation in a teaching hospital in Saudi Arabia: a retrospective study. Saudi J Anaesth 2017; 11(4): 415-420.

[5] Gruber C, Nabecker S, Wohlfarth P, Ruetzler A, Roth D, Kimberger O, Fischer H, Frass M, Ruetzler K. Evaluation of airway management associated hands-off time during cardiopulmonary resuscitation: a randomised manikin follow-up study. Scand J Trauma Resusc Emerg Med 2013; 21: 10.

[6] Lurie K, Nemergut E, Yannopoulos D, Sweeney M. The Physiology of Cardiopulmonary Resuscitation. Anesth Analg 2016; 122(3): 767-783.

[7] Wang HE, Simeone SJ, Weaver MD, Callaway CW. Interruptions in cardiopulmonary resuscitation from paramedic endotracheal intubation. Ann Emerg Med 2009; 54(5): 645-652.e1.

[8] Gaszynska E, Gaszynski T. The influence of different airway management strategies on chest compression fraction in simulated cardiopulmonary resuscitation, provided by paramedics: LMA supreme versus endotracheal intubation and combitube. Sina Vitae 2014; 9(1): 22-26.

[9] Soar J, Nolan JP, Bottiger BW, Perkins GD, Lott C, Carli P, Pellis T, Sandroni C, Skrfvars MB, Smith GB, Sunde K, Deakin $C D$, Adult advanced life support section Collaborators. European Resuscitation Council Guidelines for 


\section{The Outcomes of Endotracheal Intubation Versus Non-Endotracheal Intubation During Cardiopulmonary Arrest in the ER Dept. A.A. Bakhsh et al.}

Resuscitation 2015: Section 3. Adult advanced life support. Resuscitation 2015; 95: 100-147.

[10] Gupta DM, Boland RJ Jr, Aron DC. The physician's experience of changing clinical practice: a struggle to unlearn. Implement Sci 2017; 12(1): 28.

[11] Hanif MA, Kaji AH, Niemann JT. Advanced airway management does not improve outcome of out-ofhospital cardiac arrest. Acad Emerg Med 2010; 17(9): 926931.

[12] Studnek JR, Thestrup L, Vandeventer S, Ward SR, Staley K, Garvey L, Blackwell T. The association between prehospital endotracheal intubation attempts and survival to hospital discharge among out-of-hospital cardiac arrest patients. Acad Emerg Med 2010; 17(9): 918-925.

[13] Nagao T, Kinoshita K, Sakurai A, Yamaguchi J, Furukawa M, Utagawa A, Moriya T, Azuhata T, Tanjoh K. Effects of bag-mask vs advanced airway ventilation for patients undergoing prolonged cardiopulmonary resuscitation in pre-hospital setting. J Emerg Med 2012; 42(2): 162-170.

[14] Shin SD, Ahn KO, Song KJ, Park CB, Lee EJ. Out-of-hospital airway management and cardiac arrest outcomes: a propensity score matched analysis. Resuscitation 2012; 83(3): 313-319.

[15] Egly J, Custodio D, Bishop N, Prescott M, Lucia V, Jackson RE, Swor RA. Assessing the impact of prehospital intubation on survival in out-of-hospital cardiac arrest. Prehosp Emerg Care 2011; 15(1): 44-49.

[16] Wang H, Szydlo D, Stouffer JA, Lin S, Carlson JN, Vaillancourt C, Sears G, Verbeek RP, Fowler R, Idris AH, Koenig K, Christenson J, Minokadeh A, Brandt J, Rea T; ROC Investigators. Endotracheal intubation vs supraglottic airway insertion in out-of-hospital cardiac arrest. Resuscitation 2012; 83(9): 1061-1066.

[17] Hasegawa K, Hiraide A, Chang Y, Brown DF. Association of prehospital advanced airway management with neurologic outcome and survival in patients with out-ofhospital cardiac arrest. JAMA 2013; 309(3): 257-266.

[18] Pandian GR, Thampi SM, Chakraborty N, Kattula D, Kundavaram PP. Profile and outcome of sudden cardiac arrests in the emergency department of a tertiary care hospital in South India. J Emerg Trauma Shock 2016; 9(4): 139-145.

[19] KayserRG,OrnatoJP,PeberdyMA;AmericanHeartAssociation National Registry of Cardiopulmonary Resuscitation. Cardiac arrest in the Emergency Department: a report from the National Registry of Cardiopulmonary Resuscitation. Resuscitation 2008; 78(2): 151-160.

[20] Cummins RO, Chamberlain D, Hazinski MF, Nadkarni V, Kloeck W, Kramer E, Becker L, Robertson C, Koster $\mathrm{R}$, Zaritsky A, Bossaert L, Ornato JP, Callanan V, Allen M, Steen P, Connolly B, Sanders A, Idris A, Cobbe S. Recommended Guidelines for Reviewing, Reporting, and Conducting Research on In-Hospital Resuscitation: The In-Hospital 'Utstein Style'. Circulation 1997; 95(8): 2213-2239.
[21] Schefold JC, Storm C, Kruger A, Ploner CJ, Hasper D. The Glasgow Coma Score is a predictor of good outcome in cardiac arrest patients treated with therapeutic hypothermia. Resuscitation 2009; 80(6): 658-661.

[22] Hifumi T, Kuroda Y, Kawakita K, Sawano H, Tahara Y, Hase M, Nishioka K, Shirai S, Hazui H, Arimoto H, Kashiwase K, Kasaoka S, Motomura T, Yasuga Y, Yonemoto N, Yokoyama $\mathrm{H}$, Nagao K, Nonogi H; J-PULSE-Hypo Investigators. Effect of admission Glasgow Coma Scale Motor Score on neurological outcome in out-of-hospital cardiac arrest patients receiving therapeutic hypothermia. Circ J 2015; 79(10): 2201-2208.

[23] Benoit JL, Gerecht RB, Steuerwald MT, McMullan JT. Endotracheal intubation versus supraglottic airway placement in out-of-hospital cardiac arrest: A metaanalysis. Resuscitation 2015; 93: 20-26.

[24] Tortolani AJ, Risucci DA, Rosati RJ, Dixon R. In-hospital cardiopulmonary resuscitation: patient, arrest and resuscitation factors associated with survival. Resuscitation 1990; 20(2): 115-128.

[25] Hajbaghery MA, Mousavi G, Akbari H. Factors influencing survival after in-hospital cardiopulmonary resuscitation. Resuscitation 2005; 66(3): 317-321.

[26] Shih CL, Lu TC, Jerng JS, Lin CC, Liu YP, Chen WJ, Lin FY. A web-based Utstein style registry system of in-hospital cardiopulmonary resuscitation in Taiwan. Resuscitation 2007; 72(3): 394-403 


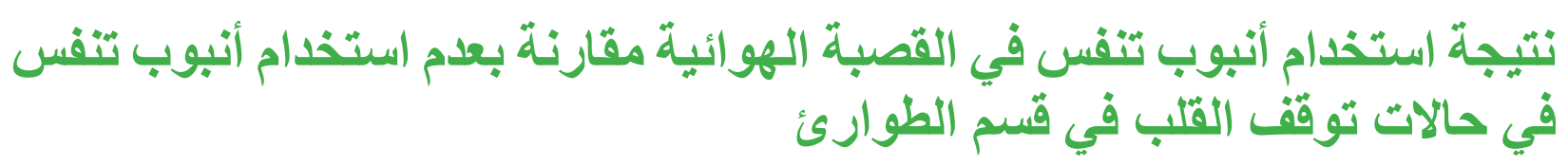

عبدالله عبدالرحمن بخش' و دانيا سمير اللاليَ' و احمد حسن باخريبة' و علي احمد الفيضيّ"

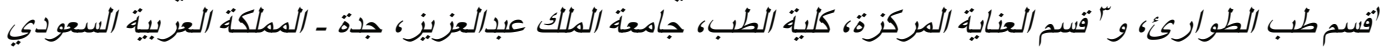

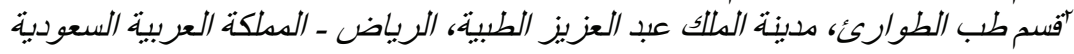

المستخطص. تقنيات أداره المجاري الهو ائية اثناء توقف القلبي الرئوي في أداره الطو ارئ قد تؤثر علي نتائج قصيرة وطويلة

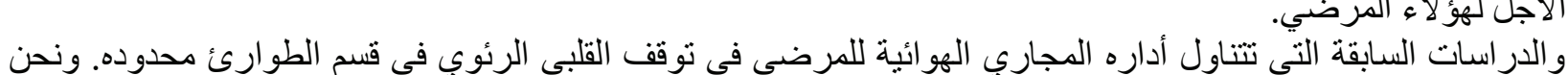

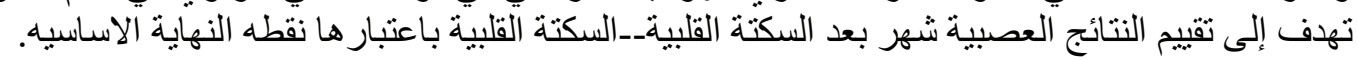

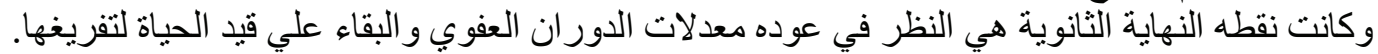



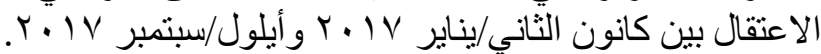

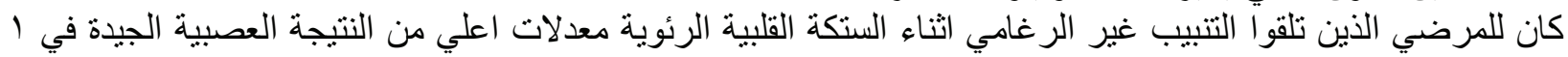

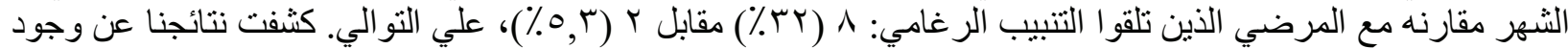

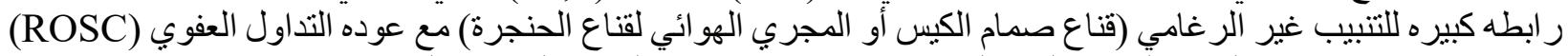

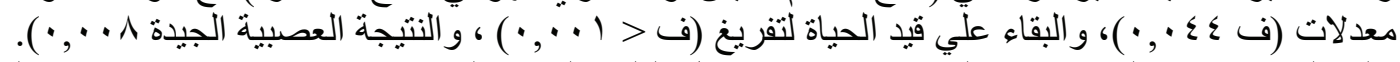

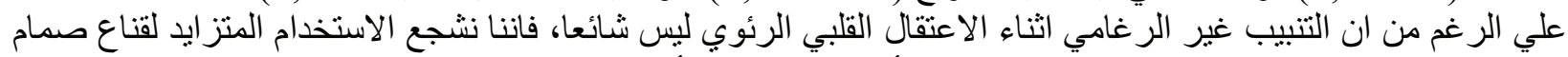

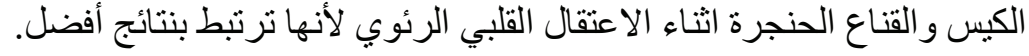

